\title{
O CONCEITO DE NATUREZA COMUM EM DUNS ESCOTO*
}

Cesar Ribas Cezar**

SÍNTESE - Ante o fato de que as coisas são singulares e o conhecimento científico é universal, Duns Escoto, preocupado em fundamentar a possibilidade da ciência, coloca-se a questão: a natureza, em si mesma, é individual ou universal? Sua resposta, acompanhando a de Avicena, é a de que a natureza, em si mesma, não é nem universal, nem singular, mas indiferente a ambas.

\begin{abstract}
Aware of the fact that things are singular and that scientific knowledge is universal, Duns Scotus, wanting to establish on a base the possibility of science, asks himself whether nature in itself is singular or universal. Following Avicenna, the Doctor subtilis answers that nature per se never is universal nor singular, but indifferent towards every one of the alternatives.
\end{abstract}

\section{I - Colocação do problema}

Duns Escoto trata da noção de natureza na Ordinatio II, d. 3, p. 1, q. I. ${ }^{1}$ Esta distinção discute diretamente o princípio da individuação. Na primeira questão ele se pergunta "se a substância material é individual ou singular por si mesma ou por sua natureza" ( $\$ 1)$. Em outros termos, se a natureza é individual em si mesma. Como vemos, ela se refere diretamente à primeira alternativa da clássica pergunta de Avicena: a essência é individual ou universal? A segunda alternativa, isto é, se a natureza é universal em si mesma, também é tratada nesta questão $(\S 35,37$ e 38), embora com menos detalhe que a primeira. Vemos, portanto, que Escoto segue a formulação aviceniana do problema. Sua resposta, também seguindo Avicena, negará ambas alternativas. A natureza não é em si mesma nem singular nem universal, mas indiferente ou comum à singularidade e à universalidade. Além disso, ele tentará mostrar que esta natureza é, de algum modo, real; o que não significa que ele diga que ela é "existente" ou que o universal é real fora da alma.

\footnotetext{
* Este estudo foi retirado da dissertação de mestrado O conhecimento abstrativo em Duns Escoto, publicado pela EDIPUCRS (1996).

** Mestre, UNICAMP.

1 As referências a este texto serão indicadas somente pelo número do parágrafo da edição Vaticana.
}

\begin{tabular}{|l|l|l|l|l|l|}
\hline VERITAS & Porto Alegre & v. 41 & $\mathrm{n}^{0} 163$ & Setembro 1996 & p. 447-456 \\
\hline
\end{tabular}


A solução escotista desta questão parece, porém, estar condicionada por uma tese básica sobre o conhecimento abstrativo intelectual (e científico): o conhecimento intelectual por conceitos universais não é uma pura ficção do intelecto e possui uma referência nas coisas ( $\$ 23$ ). Ora, para que o conhecimento intelectual possua esta referência na realidade concreta, ele não pode ser totalmente distinto das coisas tal como elas são. Em algum aspecto, deve haver uma identidade entre a coisa nela mesma e o conhecimento na alma. E não basta dizer que há uma semelhança entre a coisa e o conhecimento, pois quem diz "semelhante" diz "idêntico sob um aspecto" e "distinto sob outro". Portanto, em algum aspecto deve haver uma verdadeira identidade entre a coisa e o conhecimento. Ora, a coisa existente é singular e o conhecimento é universal. Logo, o aspecto no qual são idênticos não pode ser nem singular nem universal, pois se for singular, ele não poderá ser universal e vice-versa, e, portanto, não haverá identidade, nem conhecimento. Este aspecto deve ser neutro ou indiferente ou comum em relação à universalidade e à singularidade. Este aspecto comum é a natureza ou qüididade.

A natureza comum deve, portanto, ser algo real nas coisas concretas. Caso contrário, o conhecimento intelectual (e científico) não possuirá nenhuma referência nelas.

Por outro lado, a natureza comum deve ser aquilo que há de necessário na coisa e que permite a fundação do conhecimento científico, ou seja, aquilo que é captado pelo conhecimento abstrativo. ${ }^{2}$

Vejamos se estas hipóteses não são desmentidas pela análise deste texto.

\section{II - Argumentos iniciais}

Inicialmente, o Doutor Sutil expõe a posição daqueles que afirmam que a natureza é individual ou singular em si mesma.Aristóteles sustenta no livro VII da Metafísica que "a substância de qualquer coisa é própria daquela da qual é, e não está em outra". Assim, a substância por sua própria natureza não pode estar em outra coisa além daquela em que está, ou seja, ela é por sua própria natureza individual (§ 2). Esta opinião, como se pode ver na sua exposição mais à frente, sustenta que a natureza da substância é causa suficiente da singularidade da coisa e não lhe é necessário acrescentar nada para se tornar singular (§ 5). Assim, não há como procurar uma causa da singularidade além da natureza da coisa; o problema está na universalidade da natureza, pois se esta é em si singular, devemos procurar uma causa que a torne universal na alma (§6).

Em seguida, ele passa a apresentar os argumentos contrários a esta tese.

Em primeiro lugar, se algo é um elemento essencial de alguma coisa, por definição, sempre que encontrarmos esta coisa encontraremos este algo. Assim, se a singularidade é um elemento essencial da natureza, sempre que encontrarmos a natureza encontraremos a singularidade. Por exemplo, se a natureza da pedra é em si singular, ou seja, é em si "esta", sempre que encontrarmos a natureza da pedra,

2 As hipóteses levantadas se referem ao conhecimento intelectual humano "pro statu isto", isto é, ao conhecimento intelectual preso à sensibilidade e incapaz de captar a singularidade das coisas. V. sobre o atual estado do intelecto humano, Dumont, R.: Scotus intuition in the light of the intellects present state, in De doctrina Ioannis Duns Scoti, V. II, p. 47-64. 
encontraremos "esta pedra" singular (§ 3). Em outras palavras, se a natureza em si é única em número, ela não pode ser muitas sem ser contraditória consigo mesma ( $\S$ 4). Em suma, por esta tese haveria uma única pedra, um único cavalo, um único homem. O que é absurdo.

O segundo argumento só aparece na refutação da primeira opinião. Se a natureza é em si singular, o intelecto, ao inteligir a natureza como universal, a intelige não somente de um modo diferente do que ela é, mas, além disso, de um modo oposto e contraditório com o modo pelo qual ela é em si mesma (§ 7). Desta forma, o conhecimento intelectual das naturezas é sempre falso. O que também é absurdo. Aqui, já encontramos uma confirmação da hipótese inicial. A natureza comum é condição de possibilidade do conhecimento intelectual verdadeiro, isto é, do conhecimento intelectual que possua uma referência nas coisas.

$O$ terceiro argumento vai se estender por quase toda a questão. Ele se inicia assim: se a unidade própria, real e suficiente de algo é menor que a unidade numérica, então este algo é uno em uma unidade menor que a numérica, isto é, este algo não é em si "este". Ora, a unidade própria da natureza é menor que a unidade numérica. Portanto, a natureza é una em uma unidade menor que a numérica, isto é, ela não é de si "esta". E, assim, a natureza não é causa suficiente da singularidade (§ 8).

Mas, antes de prosseguir analisando este argumento, convém examinar o que Duns Escoto entende por unidade real e unidade numérica.

\section{III - Unidade real e unidade numérica}

Temos uma primeira pista na Ordinatio I, d. 2, p. 2, q. 1-4, que trata das distinções entre as pessoas divinas. Duns Escoto estabelece alí uma classificação dos graus de unidade. O mais baixo grau de unidade é a unidade do agregado, isto é, dos objetos simplesmente reunidos. Acima desta está a unidade de ordem, isto é, onde o conjunto não é uma simples reunião, mas obedece a uma ordem e cada parte tem sua posição determinada em virtude desta ordem.Acima, está a unidade por acidente, que é a unidade de uma substância e seu acidente. Acima, está a unidade por si, isto é, a unidade entre os elementos essênciais de uma substância. Ainda acima está a unidade do simples, onde temos uma verdadeira identidade, pois no interior do simples qualquer parte é a mesma coisa que qualquer outra parte. Por fim, está a identidade formal onde o idêntico inclui o idêntico em sua razão formal. ${ }^{3}$

Este último grau mostra que para Escoto a cada tipo de identidade corresponde um tipo de unidade, que funda esta identidade 10 que é também confirmado pelo argumento no $§ 18$ da

3 Duns Scotus, I. "...possumus invenire in unitate multos gradus - primo, minima est aggregationis; in secundo gradu est unitas ordinis, quae aliquid addit supra aggregationem; in tertio est unitas per accidens, ubi ultra ordinem est informatio, licet accidentalis, unius ab altero eorum quae sunt sic unum; in quarto est per se unitas compositi ex principiis essentialibus per se actu et per se potentia; in quinto est unitas simplicitatis, quae est vere identitas (quidquid enim est ibi, est realiter idem cuilibet, et non tantum est unum illi unitate unionis, sicut in aliis modis) - ita, adhuc ultra, non omnis identitas est formalis. Voco autem identitatem formalem, ubi illud quod dicitur sic idem, includit illud cui sic est idem, in ratione sua formali quiditativa et per se primo modo." Ordinatio I, d. 2, p. 2, q. 1-4, n. 403, ed Vat. vol. 2 . 
questão em pauta). Igualmente, a cada tipo de identidade corresponde um tipo de distinção. Distinto, com efeito, é o não idêntico. Assim, ao definirmos uma unidade, definimos ao mesmo tempo uma identidade e uma distinção; ao definirmos uma distinção, definimos uma identidade e uma unidade; e ao definirmos uma identidade, definimos uma unidade e uma distinção. Podemos, portanto, desde já concluir que no pensamento escotista existem diversos graus de identidade, unidade e diversidade proporcionais um ao outro.

Entretanto, não encontramos nesta classificação a definição que nos interessa diretamente, isto é, a de unidade real. Mas, encontramos neste mesmo texto outras definições que podem nos ajudar a construir este conceito.

Encontramos, inicialmente, uma definição de "real". Real é aquilo que precede todo ato do intelecto. Em outras palavras, uma entidade é real quando ela se dá mesmo que nenhum ato do intelecto a considere. ${ }^{4}$

Logo em seguida, Duns Escoto afirma que entre as pessoas divinas há uma distinção real, pois a mesma pessoa não é formalmente a outra. Se fossem formalmente idênticas não seria possivel distinguí-las. ${ }^{5}$

Esta distinção entre as pessoas divinas é a menor dentre as distinções reais, isto é, entre as que precedem todo ato do intelecto. ${ }^{6}$ Ela não deve ser confundida com a distinção real atual, isto é, com a distinção entre duas coisas que atualmente existem uma à parte da outra, pois as pessoas divinas não são atualmente distintas. ${ }^{7}$ Ela poderia até mesmo ser chamada de "distinção de razão", se o termo "razão" fosse entendido como a qüididade da coisa e não somente como algo formado no intelecto. ${ }^{8}$

Em suma, a distinção, ou melhor, a não-identidade real, é aquela que se dá independente de qualquer ato do intelecto. Duas qüididades podem ser realmente distintas, mesmo que não existam atualmente separadas uma da outra. A vontade e a inteligência deste homem, por exemplo, são realmente distintas, pois a diferença entre elas precede qualquer ato do intelecto, isto é, a vontade continuaria a ser diferente da inteligência mesmo que esta diferença nunca fosse conhecida.

4 Duns Scotus, I. "et intelligo sic realiter, quod nullo modo per actum intelectus considerantis, immo quod talis entitas esset ibi si nullus intellectus esset considerans; et sic esse ibi, si nullus intellectus consideraret, dico esse ante omnem actum intelectus." Ordinatio I, d. 2, p. 2, q. 1-4, n. 390, ed. Vat. vol. 2.

5 Duns Scotus, I. "... distinctio divinonum suppositorum est realis; ergo cum non possit idem eodem formaliter, quod est aliquid sui, convenire realiter tantum, sic quod non ex illo distingui, et diferre realiter tantum, sic quod non ille convenire (quia si est omnino idem re, quare hoc est tantum principium identitatis et non-identitatis et idem tantum principium distinctionis et non-identitatis), ..." Ordinatio I, d. 2, p. 2, q. 1-4, n. 398, ed. Vat. vol. 2.

Duns Scotus, I, "... differentia hic intenta, quae est immanifesta, nimirum quia minima in suo ordine, id est inter omnes quae praecedunt intellectionem." Ordinatio I, d. 2, p. 2, q. 1-4, n. 397, ed. Vat. vol. 2.

Duns Scotus, I, "Sed numquid haec distinctio dicetur realis? Respondeo: non est realis actualis, intelligendo sicut comuniter dicitur, 'differentia realis actualis' illa quae est differentia rerum et in actu, quia in una persona non est aliqua differentia rerum, propter simplicitatem divinam..." Ordinatio I, d. 2, p. 2, q. 1-4, n. 400 , ed. Vat. vol. 2. dum quod quiditas est obiectum intellectus" Ordinatio I, d. 2, p. 2, q. 1-4, n. 401, ed. Vat, vol. 2. 
Diante disto, podemos definir a identidade real como aquela que precede qualquer ato do intelecto e, conseqüentemente, a unidade real como aquela que precede qualquer ato do intelecto. A unidade real, portanto, não é somente aquela da coisa que existe atualmente à parte, mas é a unidade de tudo que se dá independente do ato do intelecto. Por contraste, podemos definir a entidade de razão, propriamente dita, como aquela que só existe no modo de conceber o objeto. Conseqüentemente, a unidade de razão é aquela que só existe no modo de conceber. ${ }^{9}$

A unidade numérica e a unidade menor que a numérica, por sua vez, não são analisadas neste texto sobre as distinções das pessoas divinas. Provavelmente, a unidade numérica corresponde à unidade real atual e a unidade menor que a numérica corresponde a unidade formal.

Mas voltando à Ordinatio II, d. 3, q. 1, encontramos no já citado parágrafo 8 uma primeira indicação: "não é de si uno em unidade numérica (ou, não é, de si, isto)". Ora, ser "isto" é ser singular ou individual. Podemos, portanto, dizer que a unidade numérica é aquela própria ao individuo e que a distinção numérica é aquela segundo a qual um indivíduo é distinto do outro enquanto indivíduo. Esta distinção parece ser a distinção real atual, pois um indivíduo só é distinto do outro se ele existe atualmente à parte do outro e um ente só existe atualmente à parte de outro se ele é um indivíduo distinto do outro.

Para definirmos a unidade menor que a numérica, temos antes que esclarecer o que Duns Escoto entende por unidade maior e unidade menor. Encontramos este esclarecimento no parágrafo seguinte (§ 9). Com efeito, ele afirma aí que "uma multidão oposta à unidade maior pode estar junto à unidade menor, multidão que não pode estar junto à unidade maior". Isto é, se dissermos que muitos indivíduos são um indíviduo, estaremos sendo contraditórios, pois a multiplicidade e a unidade não podem estar juntas no mesmo tipo de unidade. Mas, se dissermos que muitos indivíduos são um único agregado, não há contradição, pois multiplicidade de indivíduos não é contraditória com a unidade do agregado. $E$ assim pode-se dizer que uma unidade é menor que outra quando a multiplicidade própria à unidade maior (muitos indivíduos) pode estar junto da menor (o agregado). Podemos, portanto, definir a unidade menor que a unidade numérica como aquela que é compativel com a multiplicidade de indivíduos.

\section{IV - As naturezas são reais}

Feitos estes esclarecimentos, podemos retomar o argumento principal. Foi dito, com efeito, que se a unidade própria de algo é menor que a unidade numérica este algo não é por si individual, o que é claro, pois se a unidade menor que a unidade numérica é compatível com a multiplicidade de indivíduos, ela não pode ser em si a unidade individual (§9). Foi dito também que a unidade da natureza é menor

9 V. sobre as distinções em Duns Escoto Et. Gilson: Jean Duns Scot - Introduction à ses positions fondamentales, Vrin, Paris, 1952. p. 243-254. Não se deve interpretar as distinções escotistas colocando de um lado a distinção de razão, de outro a distinção real e no meio a distinção formal. $\mathrm{Na}$ verdade, a distinção real é um gênero, do qual são espécies a distinção formal, a distinção real atual, a distinção modal, etc. 
que a numérica e que, portanto, a natureza não é por si individual. (§ 8) Esta segunda afirmação exige uma prova.

Ela se inicia no § 10. Duns Escoto: "se nenhuma unidade real da natureza é menor que a singularidade e se toda unidade da natureza específica, distinta da unidade da singularidade é menor que unidade real,- então não haverá nenhuma unidade real menor que a unidade numérica; o conseqüente é falso como provarei por cinco ou seis vias; portanto etc."

O argumento é elíptico, mas a intenção do Doutor Sutil é clara. Ele pretende, através das "cinco ou seis vias", mostrar que, além da unidade numérica, própria ao indivíduo, realmente há uma unidade menor que a numérica, própria à natureza (§ 10).

Ora, mostrar isto é mostrar que, além dos indivíduos, há certas entidades nãoindividuais em si, as naturezas comuns ou qüididades, que merecem ser chamadas de "reais", pois existem (em sentido lato, isto é, "são", mas não atualmente ou efetivamente) independentes de qualquer ato do intelecto. Logo, as "cinco ou seis vias" mostram também a realidade das naturezas. Passemos, portanto, ao exame delas.

Todas as provas da realidade de uma unidade real e menor que a numérica terão a seguinte estrutura: primeiro se prova que um fato qualquer exige uma certa unidade, em seguida que esta unidade é real e, por fim, que não é numérica.

A primeira afirma que em todo gênero existe um primeiro que serve de medida a tudo que está naquele gênero (§ 11). Este primeiro é uno, pois conforme Aristóteles, toda primeira razão de medida é una. Ora, é uma unidade real, pois as coisas medidas são reais e são realmente medidas. Como entes reais não podem ser realmente medidos por entes de razão, então a unidade do primeiro mensurante é real (§ 12). Além disso, não é uma unidade numérica, pois o primeiro mensurante no gênero não é um singular. O que Aristóteles confirma no livro III da Metafísica ao dizer que "nos indivíduos da mesma espécie, não é este anterior e aquele posterior". Portanto, é uma unidade real não numérica. (§ 13) Como se pode ver, o argumento repousa sobre a afirmação de que entes reais não podem ser realmente medidos por entes de razão. O que Duns Escoto entende por "realmente medidos" não é explícito no texto, mas como "real" é geralmente usado para designar aquilo que precede qualquer ato do intelecto, podemos entender "realmente medidos" como uma medida que precede qualquer ato do intelecto e que subsiste em si mesma, mesmo que não seja conhecida.

Em segundo lugar, na espécie, onde os singulares podem ser comparados entre si, há uma unidade de natureza (§ 16). Esta não é uma unidade de razão, pois há uma diferença entre a unidade da espécie e a unidade do gênero, já que o gênero pode ser predicado quiditativamente de muitas espécies. Ora, se estas unidades fossem de razão não haveria esta diferença, pois no intelecto tanto o gênero quanto a espécie possuem a mesma unidade. Portanto, a espécie possui uma unidade real. Além disso, esta unidade não é numérica, pois se fosse, ela seria singular, e haveria uma comparação entre singulares dentro de um singular, o que é absurdo. Portanto, na espécie há uma unidade real não numérica (§ 17).

Em terceiro lugar, as relações de semelhança e de igualdade são baseadas em uma unidade. Ora, estas relações são reais, isto é, precedem qualquer ato do inte- 
lecto. Mas, uma relação só é real se ela está baseada em algo real. Assim, a unidade em que se fundam estas relações é réal. Além disso, a unidade não é numérica, pois não pode haver uma relação entre duas coisa, se estas duas são uma única e mesma coisa. Em outras palavras, nada pode ser igual ou semelhante a si mesmo. Portanto, nestas relações há uma unidade real não numérica (§ 18).

Em quarto lugar, numa oposição real (por ex.: o branco e o preto, o quente e 0 frio) a contrariedade é real, pois um oposto destrói o outro sem qualquer intervenção do intelecto. Assim sendo, cada oposto é real. Ora, cada oposto possui uma unidade, portanto possui uma unidade real. Mas, a unidade não é numérica, pois, se fosse numérica, somente este branco singular seria oposto a este preto singular, o que é falso, pois todo e qualquer branco é oposto a todo e qualquer preto (§ 19).

Em quinto lugar, toda faculdade sensitiva possui um objeto próprio distinto do objeto das outras faculdades (por ex.: a cor e o som). Assim, estes objetos possuem uma unidade real. Ora, esta unidade não é numérica, pois, se fosse, o objeto, por exemplo, da visão seria apenas este colorido singular, e não os coloridos em geral. Portanto, o objeto das faculdades dos sentidos possuem uma unidade real não numérica. ${ }^{10}$

Além disso, o objeto de um único ato do sentido possui uma unidade que não é numérica. Com efeito, se o objeto de um único ato do sentido possuisse uma unidade numérica, o sentido o conheceria como distinto de qualquer outro, distinto dele numericamente. Ora, o sentido não conhece o objeto na medida em que ele é numéricamente distinto de outro. Se, por exemplo, Deus, em sua potência absoluta, criasse no mesmo local, no mesmo tempo, dois brancos iguais na brancura, a visão não conseguiria distinguí-los. Ela, portanto, não é capaz de conhecer seus objetos na medida em que eles são numericamente distintos. Logo, o objeto de seu ato não possui uma unidade numérica. Mas este objeto possui uma unidade real. Portanto, há alguma outra unidade real distinta da numérica (§ 20 e 21).

Em sexto lugar, se a única unidade real é a numérica, então toda diversidade real é numérica, pois a cada unidade corresponde uma diversidade própria. Ora, a diversidade numérica, enquanto numérica, é sempre igual. Mas, se toda diversidade real é numérica e a diversidade numérica é sempre igual, então todas as coisas são diversas da mesma maneira. Desta forma, Sócrates é diferente de Platão da mesma maneira que Sócrates é diferente de uma linha. Ora, se todos são igualmente diversos, não há nenhuma razão real para abstraír algo em comum de Sócrates e Platão, e não abstrair este mesmo algo de Sócrates e uma linha. Tal diferença é totalmente arbitrária. Em suma, todo universal seria uma pura ficção do intelecto, sem nenhuma relação com o real (§ 23-27).

Estas últimas conclusões são de tal forma absurdas para Duns Escoto que ele nem se preocupa em refutá-las. Para ele, se alguém se recusa a admitir que há realmente, isto é, antes de qualquer ato do intelecto, um algo a mais entre Sócrates e Platão do que entre Sócrates e uma linha, não há muito o que se discutir. Mas, se se aceita este fato, então se aceita que há unidades reais não numéricas e que os conceitos universais não são pura ficção do intelecto.

10 V. Gilson, E.: Jean Duns Scot..., p. 111 e § 22. 
Ele ainda apresenta um sétimo argumento, para mostrar a existência, em sentido lato, de uma unidade real entre duas coisas, unidade que não é numérica já que se refere a duas coisas. Numa geração univoca (por ex.: o fogo gerando o fogo) há uma unidade entre o gerador e o gerado, unidade que não é produzida pelo intelecto e portanto, é real. Portanto, também neste caso, há uma unidade real não numérica ( $\$ 28)$.

$\mathrm{E}$ assim, por estas "cinco ou seis vias", que na verdade são sete, ele prova a existência, em sentido lato, de unidades reais menores que a numérica e, portanto, que certas entidades não-singulares, as naturezas ou qüididades, são reais, isto é, existem independentes de qualquer ato do intelecto.

\section{V - Esclarecimentos}

A natureza, para Duns Escoto, não é em si nem singular nem universal. Assim como Avicena sustentava que "a eqüinidade é somente eqüinidade, - não é de si nem una nem muitas, nem universal nem particular", ele entende que a natureza é indiferente, é neutra em relação à singularidade e à universalidade, enfim, que a natureza é algo de comum entre ambas. $(\S 30,31)$. Esta natureza, entretanto, não deve ser entendida como substância primeira, pois, de fato, a substância primeira de Sócrates não pode ser a mesma substância primeira de Platão; enquanto a natureza é comum a ambos (\$ 41).

Podemos dizer, por conseguinte, que se a natureza é comum ao singular e ao universal, ela é de certa forma anterior a eles. Aqui podemos insistir na hipótese inicial. Para que o conhecimento tenha uma relação com as coisas e não seja uma pura ficção do espírito, é necessário que haja algo em comum entre as coisas singulares e os conceitos universais no intelecto. Este algo em comum, portanto, deve ser anterior tanto ao singular quanto ao universal, pois, se for um deles, não poderá ser o outro e, portanto, não haverá comunicação entre o singular e o universal.

Aqui, entretanto, surge uma dificuldade. Duns Escoto afirma que a natureza não pode ser realmente sem a singularidade e sem a universalidade (§ 32). Não se deve, portanto, hipostasiar as naturezas, atribuindo-lhes uma existência independente das coisas singulares e do intelecto que as concebe, tal como seriam as idéias platônicas, segundo Aristóteles. Mas, por outro lado, em toda a questão ele está tentando mostrar que a natureza é anterior e indiferente à singularidade e à universalidade. Logo, ela deve possuir alguma realidade que lhe seja própria.

O Doutor Sutil, portanto, parece trabalhar com duas noções de realidade. Uma é realidade própria à natureza em si mesma; uma realidade, por assim dizer, formal. Outra é a realidade que a natureza não possui em si mesma, mas só quando estiver junto com a singularidade ou com a universalidade no intelecto; uma realidade plena, por assim dizer, e que merece propriamente ser chamada de "existente".

A natureza é, portanto, em si, uma realidade formal, mas não é uma realidade existente. Em outras palavas, a natureza é real naquela realidade que the é própria, isto é, na realidade formal, mas não é só por si real na realidade existente. Mas, parece ficar ainda uma dúvida: sendo a natureza formalmente real, ela é realmente real? Esta questão é sem sentido, pois tanto a realidade formal quanto a realidade 
existente são reais, cada uma a seu modo. Também não há muito sentido em se perguntar se a natureza é em si uma realidade existente, pois seria perguntar se algo possui, em próprio, uma realidade que não lhe é própria. Seria o equivalente a perguntar se uma linha em si cheira rosa ou jasmim. ${ }^{11}$

Do mesmo modo que a natureza só possui em si aquela realidade que the é própria, ela só possui em si a unidade que lhe é própria. Ora, a unidade que lhe é própria não é a numérica, pois não lhe repugna que seja colocada junto a uma multiplicidade de singulares. Ela também não é de si múltipla em multiplicidade numérica, pois não lhe é necessário estar em muitos indivíduos. É assim que, para o Doutor Sutil, devemos entender a tese de Avicena. A eqüinidade não possui em si nem a unidade numérica nem a multiplicidade numérica, não é nem universal nem particular. Ela só possui aquela unidade que lhe é própria (§ 31).

Mas, por que a natureza não é o universal? A natureza, com efeito, é indiferente a este e àquele singular (§ 35 ) e o universal é aquilo que é uno em muitos e de muitos (§ 37). Qual é, então, a diferença entre eles? Antes de tudo, convém insistir que, no pensamento escotista, o universal também é um ente de razão, que só existe no intelecto. Tentar fazê-lo real seria criar uma quimera, pois na coisa nada há que possa ser predicado de muitos subordinados (§ 37). A natureza, por sua vez, é algo real, isto é, independente do intelecto. Mas a natureza não possui em si esta capacidade de ser predicada de muitos, ou seja, o fato da natureza não ser de si "esta", de ela poder estar em outro singular além daquele em ela está, de ela ser "comum", não implica que ela seja imediatamente predicável de muitos. Eis, portanto, a diferença entre a natureza e o universal. A natureza está em potência remota a ser predicada de muitos, o universal está em potência próxima. Para que esta potência remota seja transformada em potência próxima é necessária a ação do intelecto. $\mathrm{O}$ universal, portanto, não pode existir sem o intelecto e fora do intelecto

Podemos tentar explicar esta diferença também do seguinte modo: um universal qualquer é composto por dois elementos - sua universalidade e seu conteúdo. O universal "cavalo" e o universal "leão" são iguais na universalidade, pois ambos podem ser predicados de muitos, mas são diferentes quanto ao conteúdo, pois ser cavalo é obviamente diferente de ser leão. Este conteúdo é a natureza comum, a qüididade, ou ainda, a formalidade. Assim, a universalidade do universal, que é igual em todos os universais, é produzida pelo intelecto, mas o conteúdo do universal, que é específico de cada universal, é algo real e é aquilo que o universal tem em comum com o singular.

Devemos notar, portanto, que o universal não é uma simples ficção do intelecto. Este deve levar em conta a natureza comum, que é real, na produção do universal. A natureza, como já dissemos, possui somente uma realidade formal, e não uma realidade existente. E assim, tal como não the repugna estar totalmente no indivíduo existente, também não lhe repugna estar totalmente no universal.

11 Segundo W. Kluxen as essências (naturezas) são os entes enquanto possíveis. O mundo efetivo-contingente tem como base 0 mundo necessário das possibilidades, que é captado pelos conceitos e pela ciência. V. deste comentador: Bedeutung und Funktion der Allgemeinbegriffe in Thomistischen und Skotistischen Denken, in De Doctrina Ioannis Duns Scoti, Vol. II, p. 236-237. 


\section{VI - Conclusão}

A natureza comum é, portanto, algo anterior à universalidade e à singularidade e pode estar tanto na coisa singular quanto no conceito universal. Assim sendo, é possível que haja algo que seja "o mesmo" na coisa e no conhecimento intelectual. Além disso, a natureza comum é algo "real" nas coisas singulares, isto é, algo que está na coisa singular, independente de qualquer ato do intelecto. Logo, o conhecimento intelectual (e científico) pode se referir a algo "real" das coisas singulares, sem contradição.

\section{Bibliografia}

GILSON, Et.: Jeans Duns Scot - Introduction à ses positions fondamentales, Vrin, Paris, 1952. 